ISSN 1983-8484

Licenciado sob uma Licença Creative Commons

\title{
Perfil dos spin-offs acadêmicos: um estudo em uma incubadora de empresas de base tecnológica de Ponta Grossa, PR
}

\author{
Profile of academic spin-offs: a study in an incubator of \\ business base technology Ponta Grossa, PR
}

Andréia Antunes da Luz ${ }^{[a]}$, João Luiz Kovaleski ${ }^{[b]}$, Pedro Paulo de Andrade Júnior ${ }^{[c]}$, Mathias Televi Betim ${ }^{[d]}$

[a] Mestranda em Engenharia de Produção pelo Programa de Pós-Graduação em Engenharia de Produção da Universidade Tecnológica Federal do Paraná (UTFPR), Ponta Grossa, PR - Brasil, e-mail: andréia-luz@hotmail.com

[b] Doutor em Instrumentação Industrial pela Université Joseph Fourier, professor associado do Programa de Pós-graduação em Engenharia de Produção da Universidade Tecnológica Federal do Paraná (UTFPR), Ponta Grossa, PR - Brasil, e-mail: kovaleski@utfpr.edu.br

[c] Doutor em Engenharia da Produção pela Universidade Federal de Santa Catarina (UFSC), Professor adjunto do Programa de Pós-graduação em Engenharia de Produção da Universidade Tecnológica Federal do Paraná (UTFPR), Ponta Grossa, PR Brasil, e-mail: pedropaulo@utfpr.edu.br

[d] Mestrando em Engenharia de Produção pelo Programa de Pós-graduação em Engenharia de Produção da Universidade Tecnológica Federal do Paraná (UTFPR) - Ponta Grossa, PR - Brasil, e-mail: mathias.betim@utfpr.edu.br

\section{Resumo}

O objetivo deste estudo é apresentar o perfil dos spin-offs acadêmicos incubados. A metodologia utilizada em relação à função da sua natureza apresenta-se como básica, em relação aos seus objetivos como descritiva, em relação à estratégia se caracteriza como estudo de caso em uma Incubadora de Empresas de Base Tecnológica - IEBT. 0 procedimento técnico de coleta de dados utilizado foi a análise de conteúdo em documentos. Em grau de abrangência utilizou-se a amostra, uma Incubadora de Empresas de Base Tecnológica da cidade de Ponta Grossa, com abordagem qualitativa dos dados. Desde a sua fundação, a INTECPONTA já acolheu sete empresas. Deste total, dois não eram spin-offs acadêmicos, portanto, os resultados são referentes a cinco spin-offs acadêmicos oriundos da Universidade Estadual de Ponta Grossa. De forma sintetizada, os spin-offs acadêmicos têm idade superior a cinco anos, foram criados dentro dos laboratórios e salas de aula da universidade. De acordo com o critério do SEBRAE, são considerados micro e pequenas empresas, com aproximadamente três sócios e altamente qualificados em áreas técnicas. A maior parcela possui patentes depositadas, e quatro utilizaram ou utilizam recursos próprios. Apenas um beneficiou-se de dinheiro público com projetos contemplados pelas instituições de fomento, e nenhum recebeu apoio financeiro de capital de risco. Sobre o retorno financeiro, dois projetos realizaram testes em indústrias, mas somente um está em fase de transferir a tecnologia ou receber capital de risco, enquanto o outro está buscando apoio financeiro.

Palavras-chave: Cooperação universidade-empresa-governo. Transferência de tecnologia. Empreendedorismo. Incubadoras de empresas de base tecnológica. Spin-offs acadêmicos. 


\section{Abstract}

The objective this study is to present the profile of academic spin-offs incubated. The methodology used in relation to their nature is presented as basic in relation to their goals as descriptive in relation to the strategy is characterized as a case study in an incubator for technology-based companies - IEBT. The technical procedures for data collection, was used for content analysis of documents. Degree of coverage used in the sample, an incubator of technology-based companies in the city of Ponta Grossa, with qualitative data. Since its inception, has hosted seven INTECPONTA companies. Of this total were two non-academic spin-offs, so the results are for five academic spin-offs from the State University of Ponta Grossa. Synthesized form of the academic spin-offs are older than five years, were created in laboratories and classrooms of the university. Under the criterion of SEBRAE are considered micro and small enterprises with about three members and highly skilled in technical areas. The largest portion has patents, and four used either use its own resources, and only one benefited from public money on projects covered by the funding institutions, and none had received financial support from venture capital. On returns, two projects carried out tests on industry, this is only a phase of transferring technology or receive venture capital, and is seeking a financial support.

Keywords: Cooperation university-industry-government. Technology transfer. Entrepreneurship. Incubators of technology based companies. Academic spin-offs.

\section{Introdução}

O desenvolvimento social e econômico está sendo incorporado na realidade das universidades, e a nova missão de transformar essa nova universidade em uma instituição empreendedora sem deixar de lado o ensino qualificado está proporcionando a segunda revolução, na qual proteção intelectual, licenciamento de tecnologias e criação de spin-offs fazem parte da capitalização do conhecimento e da nova realidade das universidades.

Os spin-offs acadêmicos são empresas criadas para explorar uma propriedade intelectual gerada a partir de um trabalho de pesquisa desenvolvido em uma instituição acadêmica (SHANE, 2004).

A criação ou a criatividade destaca-se no desenvolvimento no processo de transferência de conhecimento e tecnologia. Para que esse sistema aconteça e gere benefícios e riqueza, alguns atores são necessários, como universidades e centros de pesquisa, empresas/indústrias, governo, recursos humanos e mecanismos que cooperem para a criação de produtos inovadores e competitivos.

Para um próspero processo de transferência de conhecimento e tecnologia é necessário que ocorram: pesquisa, desenvolvimento da ideia, recursos financeiros para os processos/produtos alcançarem o mercado e retorno desse investimento. No sistema brasileiro de inovação, os principais atores são: universidades e centros de pesquisa, empresas/indústrias e governo.
A universidade no papel de contribuir para a geração de conhecimento científico, formação de recursos humanos qualificados e para o progresso técnico do setor produtivo. As empresas/indústrias no papel de empregar os recursos humanos e gerar desenvolvimento para a sociedade. E o governo no papel de elaboração de políticas de apoio à cooperação entre esses atores, a chamada hélice tríplice.

Por muito tempo a universidade esteve de portas fechadas à sociedade e pouco se sabia a respeito do que ocorria dentro de suas paredes. Entretanto, esta situação começou a mudar no final do século XIX, quando o meio acadêmico passou a atuar cooperativamente com as diversas indústrias (COSTA; TORKOMIAN, 2008).

As universidades empreendedoras e o capitalismo acadêmico se dão mediante a comercialização de resultados de pesquisa e a participação nos negócios desenvolvidos por seus docentes e estudantes. Para estimular esses negócios, as universidades instalam incubadoras de empresas, exploram parques tecnológicos e adquirem posições no capital de novas empresas de base tecnológica internamente originadas, agindo a universidade, neste caso, como capitalista de oportunidades.

As incubadoras de empresas são ambientes dotados de capacidade técnica, gerencial, administrativa e infraestrutura para amparar o pequeno empreendedor. Elas disponibilizam espaço apropriado e condições efetivas para abrigar ídeias inovadoras 
e transformá-las em empreendimentos de sucesso (ANPROTEC, 2010). O contexto organizacional das Incubadoras de Empresas é caracterizado pelo mecanismo de apoio ao desenvolvimento e crescimento de projetos inovadores, e destacam-se como elemento viabilizador, proporcionando condições favoráveis ao surgimento de novos empreendimentos para o mercado.

O Brasil, em 2009, contava um quadro de 400 incubadoras e 74 parques, que já incubaram 6 mil empreendimentos inovadores (ANPROTEC, 2009). As incubadoras são instrumentos capazes de transformar ideias em negócios e o espaço ideal para o desempenho do empreendedorismo. Dentro das incubadoras as empresas nascentes encontram ambiente ideal para o seu crescimento e desenvolvimento e o tempo em que permanecem incubadas é o intervalo necessário entre a idealização e a realização do negócio.

O Paraná conta com a Rede Paranaense de Incubadoras e Parques Tecnológicos (REPARTE) e integra todos os programas de incubação do Estado e conta com incubadoras associadas localizadas em todo território paranaense. Atualmente, a REPARTE tem em seu quadro associativo 30 entidades atuando com pré-incubação e incubação de empresas. Estes habitats de inovação em sua maioria estão vinculados a Instituições de Ensino Superior, localizadas em regiões estratégicas. São 30 Incubadoras e 3 Parques Tecnológicos em 15 cidades, o número estimado de empresas incubadas é de 218 e de 193 graduadas, o faturamento bruto em 2008 da empresas incubadas foi de $\mathrm{R} \$ 11,5$ milhões e foi estimado em $\mathrm{R} \$ 240$ milhões para as empresas graduadas, gerando 1.062 postos de trabalhos diretos nas empresas incubadas e equipes de gestão das Incubadoras e Parques Tecnológicos, e 730 em relação a produtos gerados e desenvolvidos pelas empresas/projetos incubados (REPARTE, 2009).

0 contexto organizacional das incubadoras de empresas é caracterizado pelo mecanismo de apoio ao desenvolvimento e crescimento de projetos inovadores, e destacam-se como elemento viabilizador, proporcionando condições favoráveis ao surgimento de novos empreendimentos para o mercado.

As IEBTs necessitam cultivar determinadas atitudes e desenvolver algumas competências, devido à área de formação dos empreendedores revelando-se, em áreas técnicas e confirmando a importância de capacitação em gestão aos empreendedores, assim, cabe estabelecer esforços no sentido de alavancar o desempenho dos incubados. Neste contexto organizacional das IEBTs, o presente trabalho questiona o seguinte problema: Como se caracteriza esse novo tipo de empreendimento, os spin-offs acadêmicos?

Os spin-offs apresentam-se como mecanismos de desenvolvimento econômico, gerando empregos, renda e transferência de tecnologias geradas pelas universidades. E a cooperação entre a universidade-empresa-governo vem se destacando com o surgimento dos spin-offs acadêmicos, resultados de pesquisas realizadas nas universidades e centros de pesquisas. Essa iniciativa tem o propósito de fomentar um relacionamento mais empreendedor dos alunos e pesquisadores.

Para responder ao questionamento inicial, aborda-se o estudo de caso na Incubadora Tecnológica de Ponta Grossa - INTECPONTA, tendo como objetivo deste estudo apresentar o perfil dos spin-offs acadêmicos incubados.

A seguir, no segundo tópico, apresenta-se o referencial teórico sobre Cooperação UniversidadeEmpresa-Governo, Transferência de Tecnologia, Empreendedorismo e Incubadoras de Empresas de Base Tecnológica (IEBTs), os quais fundamentam o estudo. No terceiro tópico apresenta-se os procedimentos metodológicos adotado no estudo. A análise e discussão dos resultados são apresentados no quarto tópico, e, por fim, são apresentadas as conclusões do estudo e sugestões de estudos futuros.

\section{Referencial teórico}

Através da revisão da literatura existente, este tópico proporciona uma base teórica para os temas que se relacionam com o objetivo proposto desta pesquisa. Dessa forma, buscou-se apresentar as abordagens dos principais autores que embasam e justificam os temas pertinentes a esta pesquisa, tais como: Cooperação Universidade-Empresa-Governo; A Evolução da Universidade.

\section{Cooperação universidade-empresa-governo}

O conhecimento científico é considerado a mais importante matéria-prima que gera o crescimento econômico (CHIESA; PICCALUGA, 2000).

Ao final da década de 60 , os modelos lineares de inovação perderam força com o surgimento do 
Triângulo de Sábato. Em 1968, Jorge Sábato e Natalio Botana descreveram o papel da cooperação universidade-empresa na inovação tecnológica e a sua relevância para o desenvolvimento econômico e social da América Latina.

Os dois pesquisadores propuseram que para a superação do subdesenvolvimento da região, fosse realizada uma ação decisiva no campo da pesquisa científico-tecnológica. A proposta estava assentada em quatro argumentos: (i) o processo de absorção de tecnologia seria mais eficiente se o país receptor possuísse uma sólida infraestrutura científico-tecnológica; (ii) a especificidade das condições de cada país para conseguir uma absorção mais inteligente dos fatores de produção; (iii) a necessidade de expor tais bens com maior valor agregado; (iv) e o fato de que ciência e tecnologia são catalisadores da mudança social.

A partir de estudos prospectivos e tendo como horizonte o ano de 2000, autores defendiam a ideia de que a região podia e devia participar no desenvolvimento científico-tecnológico. Nesse sentido, a inserção da ciência e tecnologia era condição essencial para o processo de desenvolvimento. Esse processo resultaria da ação múltipla e coordenada de três elementos fundamentais para o desenvolvimento das sociedades contemporâneas: o governo, a estrutura produtiva e a infraestrutura científico-tecnológica.

Esse relacionamento foi representado graficamente por meio de um triângulo, com o governo ocupando o vértice superior enquanto a estrutura produtiva e a infraestrutura científico-tecnológica ocupavam os vértices da base. Nascia o Triângulo de Sábato.

Um novo papel para a universidade também é apresentado no modelo de Etzkowitza. A Hélice Tríplice é associada à segunda revolução acadêmica, na qual a universidade passa a assumir um papel no desenvolvimento econômico, a partir da transformação da pesquisa em atividade econômica. Percebe-se, a partir da análise dessas abordagens, a relevância e a importância da universidade para o desenvolvimento da sociedade, sendo que um dos mecanismos para a efetivação desse papel é a interação com o setor produtivo.

Proteção intelectual, licenciamento de tecnologias e criação de spin-offs acadêmicos fazem parte de um processo chamado "capitalização do conhecimento", e estão sendo inseridos na realidade da Universidade, produzindo uma segunda revolução na universidade, a Universidade como empreendedora, incorporando o desenvolvimento social e econômico.
Esta moldura conceitual é bastante útil para análise do caso brasileiro. A partir dos anos 1950 inicia-se no Brasil uma política científica mais articulada, com a criação de agências de fomento como a CAPES, o CNPq e o BNDES. Durante as décadas de 1950, 1960 e 1970 o ambiente de inovação esteve centrado predominantemente na esfera governamental.

Ao longo da década de 1980 uma nova onda liberal atinge todo o mundo. 0 Brasil inicia um processo de transição de um governo militar para um governo civil. Este é um período de crise. 0 Estado reduz sua participação na economia. No início dos anos 1990 já se inicia um debate sobre a abertura do mercado nacional para investimento estrangeiro e a privatização das empresas públicas. Ainda na primeira metade desta década, a economia se estabiliza e gradativamente as empresas estatais são vendidas para o capital privado.

Neste período, os centros de pesquisa das antigas estatais são esvaziados. Os compradores destas empresas não incluíram os centros de $\mathrm{P} \& \mathrm{D}$ no negócio. As empresas foram vendidas, mas os seus centros de P\&D não foram. 0 ambiente de inovação nas décadas de 1980 e 1990 foi caracterizado pela instabilidade orçamentária e pela clara separação entre as esferas institucionais acadêmica, empresarial e governamental.

Já a partir de 2000, o ambiente de C\&T se altera consideravelmente. As dotações orçamentárias voltam a ser crescentes, os fundos setoriais passam a conectar as demandas tecnológicas das antigas empresas estatais às atividades de pesquisa desempenhadas nas universidades brasileiras. Em 2004, é aprovada a Lei de Inovação, que regulamenta a interação entre os setores público e privado no que diz respeito a atividades de pesquisa, desenvolvimento e inovação.

Esse período é caracterizado pelo surgimento e o fortalecimento de estruturas híbridas como incubadoras de empresas, parques tecnológicos, escritórios de transferência de tecnologia, fundos de capital de risco, redes tecnológicas, entre outras. A partir daí, observa-se a intensificação do processo de criação de spin-offs acadêmicos.

\section{A evolução da universidade}

A importância dos spin-offs acadêmicos enquanto mecanismo de transferência de conhecimento e tecnologia não pode ser compreendida sem uma breve 
revisão da evolução das universidades nas décadas mais recentes.

Desde o século XII surgiram diversas revoluções universitárias, até ser alçado o atual modelo institucional da universidade. Naquela época, as instituições universitárias preocupavam-se essencialmente com Filosofia e Tecnologia. Entretanto, este enfoque foi se modificando, principalmente no que diz respeito às suas funções dentro de uma infraestrutura de produção de conhecimento (TERRA, 2001).

No início do século XVII, com a introdução do estudo das Ciências Físicas, a pesquisa foi considerada uma ação de consciência social, sendo a ciência encorajada, sustentada e planejada por mecenas e grupos corporativos; dentre esses, o Estado firmava-se, em escala crescente Terra (2001).

Atualmente, o Brasil apresenta 2.252 Instituições de ensino superior, de acordo com os dados da Tabela 1. Em relação à organização acadêmica, observa-se um incremento de 3,2\% no número de centros universitários em relação a 2007. No entanto, as faculdades (faculdades, escolas, institutos, faculdades integradas, centros federais de educação tecnológica e faculdades de tecnologia, DECRETO 5773/2006), conforme nos anos anteriores, mantiveram o predomínio, com cerca de 2.000 estabelecimentos, correspondente a $86,4 \%$ das IES, enquanto as universidades e centros universitários respondem por $8,1 \%$ e 5,5\%, respectivamente.

Em 2008, o Brasil alcançou o número de 30.415 artigos em periódicos internacionais indexados, correspondente a $2,63 \%$ da produção científica mundial. Em 2009, as publicações evoluíram para 32.100 artigos em periódicos internacionais indexados, levando o Brasil a ocupar o $13^{\circ}$ lugar no ranking mundial de produção científica, com uma participação de 2,7\%.

É necessário ampliar os resultados da universidade na produção de conhecimento que traga resultados sociais e econômicos para a sociedade. No entanto, pela natureza do trabalho da universidade, normalmente os impactos são observados no longo prazo (AZEVEDO, 2005). Existem dois caminhos para transferência de tecnologia entre universidade e empresas: o primeiro a partir de empresas spin-offs, que crescem e amadurecem a partir da colaboração com a pesquisa universitária; e outro a partir de colaboração direta com base em contratos de P\&D (OLIVEIRA; CAULLIRAUX, 2007).

A criação de empresas a partir de resultados de pesquisas acadêmicas (spin-offs) é uma forma de transferência de tecnologia bastante utilizada em países como EUA e Alemanha, pois propicia a geração de empregos de alta qualificação e a arrecadação de impostos. Essas empresas possuem potencial para tornarem-se exportadoras ou substituírem importações, trazendo divisas e melhorando a balança comercial do país (AZEVEDO, 2005).

Inicialmente, é importante destacar que alguns fundadores de empresas spin-offs reagem negativamente ao termo "spin-off", pois eles sentem que há a ênfase na dependência da organização de origem e que não há o reconhecimento dos sacrifícios em dinheiro, tempo e esforços geralmente requeridos para estabelecer uma nova empresa (STEFFENSEN; ROGERS; SPEAKMAN, 2000).

Através de um estudo de caso realizado em uma universidade pública brasileira, a Universidade Federal de São Carlos, Azevedo (2005) fez as seguintes considerações sobre a criação de empresas a partir de resultados de pesquisas:

a) para o surgimento dos spin-offs acadêmicos é necessário que haja a presença de entidades produtoras de conhecimento, de pesquisadores com perfil empreendedor, de organizações de apoio e de programas de financiamento;

b) as responsabilidades e os riscos inerentes à criação de empresas fica a cargo dos pesquisadores e alunos que tomaram estas iniciativas. A universidade não faz nenhum tipo de investimento, além do conhecimento transmitido a esses empreendedores;

c) a criação de spin-offs beneficia toda a sociedade, ao oferecer-lhe produtos e serviços cujo conhecimento e tecnologia são frutos de pesquisas realizadas nas universidades;

d) as empresas criadas geram empregos, onde prevalece o alto nível de qualificação. Em decorrência do ramo de atividade dessas firmas, geralmente elas empregam pouca mão de obra;

e) as relações entre as universidades e os spin-offs surgidos delas são intensas e tendem a aumentar com a evolução das empresas;

f) geralmente os pesquisadores, apesar de formarem uma empresa, mantêm seus vínculos empregatícios com a universidade. Desta forma, a ligação das empresas com as universidades tende a permanecer forte ao longo do tempo;

g) a satisfação em colocar à disposição da sociedade os resultados de suas pesquisas e a possibilidade de obter bons retornos financeiros 
são as principais motivações para a criação de empresas pelos pesquisadores;

h) há poucos incentivos no meio acadêmico para a formação de spin-offs, seja pelo excesso de burocracia, como também pela falta de uma legislação mais clara quanto à propriedade intelectual;

i) geralmente, para se constituírem, os spin-offs necessitam de suporte. Isso pode ocorrer via instalação em uma incubadora ou por meio de programas públicos de incentivos;

j) os pesquisadores consideram que é importante haver programas no meio acadêmico que incentivem o empreendedorismo. Entretanto, se observa que há poucas ações nesse sentido;

k) as principais barreiras encontradas são: a necessidade de um contínuo desenvolvimento tecnológico, a falta de capacitação gerencial por parte dos pesquisadores que decidem criar uma empresa, e as pressões sofridas no ambiente acadêmico em decorrência da cultura dessa instituição.

\section{Caracterização da pesquisa}

Neste tópico estão descritos os procedimentos metodológicos que foram utilizados para a realização desta pesquisa. Assim, aborda a caracterização da pesquisa e sua tipologia. Em relação à função da sua natureza esta pesquisa apresenta-se como básica, em relação aos seus objetivos apresenta-se como descritiva, em relação à estratégia se caracteriza como estudo de caso em uma Incubadora de Empresas de Base Tecnológica - IEBT. Em relação ao procedimento técnico de coleta de dados, foi utilizada a análise de conteúdo em documentos, através de uma revisão para a geração de informações a partir de dados oficiais da realidade da amostra selecionada, assim facilitando a análise dos dados levantados.

Em grau de abrangência utilizou-se a amostra, uma Incubadora de Empresas de Base Tecnológica da cidade de Ponta Grossa, com abordagem qualitativa dos dados.

\section{Amostra}

A pesquisa foi realizada na cidade de Ponta Grossa, PR, mais especificamente um estudo de caso na Incubadora Tecnológica de Ponta Grossa - INTECPONTA.
Incubadora tecnológica de Ponta

Grossa - INTECPONTA

É um empreendimento conjunto de diversas instituições, com apoio público e privado, com o objetivo de abrigar micro e pequenas empresas de base tecnológica. Com a função principal de amparar novas empresas em desenvolvimento de produtos ou serviços, dando facilidades, em um ambiente propício, para que esses produtos ou serviços originados de pesquisa possam alcançar consumidores em potencial, estimulando a economia da região em que estiver instalada. A INTECPONTA apoia a criação e o desenvolvimento de empresas de base tecnológica na região, preferencialmente nas áreas de Novos Materiais, Metal-Mecânica, Eletroeletrônica e Alimentos (INTECPONTA, 2009).

A incubadora busca apoio das universidades para que as empresas incubadas adquiram novas informações e agreguem mais tecnologia a seus produtos, e essa interação ocorre através do seu ambiente, estando no papel de coadjuvante na obtenção de informações e nos processos gerenciais, alimentando os incubados com informações para implementar a inovação. A atuação conjunta com as entidades promotoras tem sido um fator altamente positivo.

\section{Técnica de coleta de dados}

A geração de informações e análise dos dados ocorreu através de uma revisão de conteúdos em documentos como: relatórios anuais da incubadora, contratos de incubação, atas, relatórios técnicos financeiros e relatórios, planos de negócios e marketing e relatórios de acompanhamento dos incubados - estes são documentos oficiais da realidade da amostra selecionada. Na coleta de informações e dados buscou-se informações sobre: 0 tempo de existência; Tamanho das empresas seguindo o critério do SEBRAE; Patentes; Recursos financeiros; Perfil educacional por nível de graduação; Perfil educacional por área de formação e atuação; Número de sócios e Localização.

\section{Análise e discussão dos resultados}

Desde a sua fundação, a incubadora já acolheu sete empresas, cada qual em uma especialidade diferente, todas recebendo ações de apoio, suporte e 
consultoria de acordo com as necessidades de cada uma e dentro dos limites físicos e financeiros disponíveis. Deste total, dois não eram spin-offs acadêmicos. Nesta pesquisa buscou-se analisar os spin-offs acadêmicos, portanto, as informações apresentadas ao longo do tópico são referentes aos cinco spin-offs acadêmicos oriundos das universidades de Ponta Grossa e incubadas na INTECPONTA, conforme Quadro 1.
O tempo de existência de uma empresa é uma informação relevante, pois influencia as outras características da empresa, como o tamanho. A amostra pesquisada registra que $100 \%$ dos spin-offs acadêmicos têm idade superior a cinco anos, foram criados a partir de 2004, dentro dos laboratórios e salas de aula da Universidade. Em relação ao tamanho das empresas pesquisadas, seguindo o critério do SEBRAE, todas as

Quadro 1 - Spin-offs acadêmicos da INTECPONTA

\begin{tabular}{ll}
\hline Spin-offs Acadêmicos & Projetos \\
\hline Sofiglass & Tecnologia de materiais para aplicação como biomateriais \\
Kera vitrus & Desenvolvimento de vidrados a partir da utilização de resíduos de vidros não recicláveis \\
Nanoita & Processo inovador de síntese em materiais nanoparticulados para a indústria cerâmica de alta tecnologia \\
Spin-off de fundição & $\begin{array}{l}\text { Utilização de areia verde e pó de exaustão provenientes do processo de fundição na confecção de } \\
\text { telhas e tijolos cerâmicos ecológicos }\end{array}$ \\
Denswood & Desenvolvimento de processo inovador de adensamento de madeira "mole", principalmente o pinus \\
\hline
\end{tabular}

Fonte: INTECPONTA, 2009.

empresas são consideradas micro e pequenas e atuam em áreas tecnológicas, mas se diferenciam em relação à tecnologia utilizada em cada uma, são micro e pequenas empresas de base tecnológica. 0 tamanho da empresa foi avaliado pelo número de empregados e pelo tipo. Exemplo: indústria.

Por serem resultados de pesquisas altamente inovadoras, necessitam de proteção, patente ou licenciamento, esta proteção evita cópias de produtos e processos. Entretanto, a menor parcela dos resultados dos spin-offs acadêmicos estudados não possui patentes (próprias ou licenciadas), perfazendo um total de $40 \%$ da amostra, e para patentes depositadas (total ou partes dos produtos/processos), apresentou a maior parcela dos resultados, perfazendo um total de $60 \%$, de acordo com a Tabela 1. Para o resultado de existência de patentes depositadas (total ou partes dos produtos/processos), foram realizados em parceria com a agência de inovação da universidade.

Para alavancagem e desenvolvimento dos spin-offs acadêmicos com o propósito de se consolidarem no mercado, é necessário que haja recursos financeiros, os quais permitam investir no desenvolvimento de pesquisa científica tecnológica. Segundo os dados apresentados na Tabela 2, 20\% dos spin-offs acadêmicos da amostra utilizaram ou utilizam recursos próprios. Entretanto, 80\% beneficiaram-se de dinheiro público, ressaltando-se a importância do governo como significativa, pois os spin-offs acadêmicos obtiveram em projetos contemplados pelas instituições de fomento mais de R\$500.000,00. Destacase também que nestes spin-offs acadêmicos ocorreu a cooperação com empresa, universidade/incubadora e governo, através do CNPq e FINEP. E para capital de risco nenhum dos spin-offs acadêmicos recebeu qualquer tipo de apoio financeiro desta natureza.

O Perfil educacional por nível de escolaridade dos spin-offs acadêmicos. A qualificação dos pesquisadores/empreendedores envolvidos nas atividades está relacionada com a área de atuação e com a qualidade do produto/processo que será lançado no mercado. Os spin-offs acadêmicos da amostra são micro e pequenas empresas de base tecnológica, assim, exige-se capacidade de acompanhar o ritmo das transformações tecnológicas que ocorrem em sua área de atuação, permitindo consolidar-se no mercado ao longo do tempo. Neste contexto de constantes transformações tecnológicas, o nível de escolaridade é um fator decisivo para este ambiente inovativo e concorrencial.

Sobre o perfil educacional dos spin-offs acadêmicos da amostra, verificou-se o nível de escolaridade, e os dados são apresentados na Tabela 3. Nos resultados da amostra sobre o nível de escolaridade, 
ressalta-se a importância do nível stricto sensu (doutorado e mestrado), com 75\%, confirmando a alta qualificação dos empreendedores dos spin-offs acadêmicos que se encontram nas incubadoras de empresas do Brasil. Considerando a graduação, o resultado acumulado é de 100\%. Uma característica de destaque observada nos spin-offs acadêmicos é que eles são criados por pessoas de elevado nível educacional, reforçando a ligação existente entre os sócios e o meio acadêmico.

Tabela 1 - Existência de patentes depositadas dos spin-offs acadêmicos da INTECPONTA - 2009

\begin{tabular}{lccc}
\hline Categoria & Quantidade & \% do total & \% acumulada \\
\hline Sim & 3 & 60 & 60 \\
Não & 2 & 40 & 100 \\
\hline Totais & $\mathbf{5}$ & 100 & \\
\hline
\end{tabular}

Fonte: INTECPONTA, 2009.

Tabela 2 - Fontes de financiamento dos spin-offs acadêmicos da INTECPONTA - 2009

\begin{tabular}{lccc}
\hline Nível Educacional & Quantidade & $\begin{array}{c}\% \text { do } \\
\text { total }\end{array}$ & $\begin{array}{c}\% \\
\text { acumulada }\end{array}$ \\
\hline CNPq/FINEP & 1 & 80 & 60 \\
Próprios & 4 & 20 & 100 \\
Capital de risco & & & \\
\hline Totais & $\mathbf{5}$ & 100 \\
\hline
\end{tabular}

Fonte: INTECPONTA, 2009.

Tabela 3 - Perfil educacional por nível de escolaridade dos spin-offs acadêmicos da INTECPONTA - 2009

\begin{tabular}{lccc}
\hline Fontes & Quantidade & $\%$ do total & $\begin{array}{c}\% \\
\text { acumulada }\end{array}$ \\
\hline Doutorado & 6 & 50 & 50 \\
Mestrado & 3 & 25 & 75 \\
Especialização & 2 & 17 & 92 \\
Graduação & 1 & 8 & 100 \\
Ensino Médio & 0 & 0 & 100 \\
\hline Totais & 12 & 100 & \\
\hline
\end{tabular}

Fonte: INTECPONTA, 2009.
A identificação do perfil educacional por área de formação dos spin-offs acadêmicos da amostra, segundo os dados apresentados na Tabela 4, dá destaque para a área de exatas, mais especificamente a formação em química, com 33\%. Considerando a coluna, acumulada, as engenharias destacam-se com 58\% dos resultados da amostra. Revela ainda que $100 \%$ dos spin-offs acadêmicos são formados em áreas técnicas, confirmando a importância de apoio e capacitação em gestão aos empreendedores incubados.

Em relação à área de atuação serve como indicador para as características, como mercado alvo, necessidade de recursos financeiros e busca de mão de obra especializada. Os spin-offs acadêmicos da amostra conforme Quadro 1 - Spin-offs acadêmicos da INTECPONTA, áreas em que os spin-offs acadêmicos se enquadram são: um em biomateriais, um em nanotecnologia e três em ambiental. No caso da amostra pesquisada, verifica-se que $100 \%$ atuam em áreas tecnológicas, mas se diferenciam em relação à tecnologia utilizada em cada um.

Os resultados obtidos indicam que a maior parte dos spin-offs acadêmicos da amostra possui três sócios, o que representa $60 \%$, conforme Tabela 5. Este resultado pode estar relacionado ao fato de as pesquisas acadêmicas serem realizadas em grupos de pesquisa. Os dados apresentados são referentes a um total de doze sócios, obtidos através dos contratos de incubação.

Ressalta-se que dos cinco spin-offs acadêmicos da amostra, dois encerraram suas atividades por dificuldades encontradas. No primeiro caso, com o falecimento de um dos empreendedores/pesquisadores, os sócios decidiram encerrar o Projeto, que já tinha requerido patente junto ao INPI. E no outro caso, a responsável pelo projeto desligou-se, estando este em fase de demonstrativo.

Como somente três dos spin-offs acadêmicos da amostra estudada continuam com suas atividades, o número de empregos é igual ao número de sócios, em um total de oito sócios altamente qualificados. E em relação ao faturamento, nenhum deles o havia alcançado até o final de 2009. Um motivo para este resultado é que todos os sócios estão ligados às universidades de origem das pesquisas como professores, e o tempo dedicado ao projeto foi limitado.

Em relação à localização: dois estão incubados não residentes alocados em espaço próprio e distantes das universidades de origem da pesquisa, 
Tabela 4 - Perfil educacional por nível de escolaridade dos spin-offs acadêmicos da INTECPONTA - 2009

\begin{tabular}{llccc}
\hline Área & Curso & Quantidade & \% do total & \% acumulada \\
\hline \multirow{3}{*}{ Agrárias e Tecnológica } & Engenharia de Materiais & 2 & 17 & 17 \\
& Engenharia Civil & 2 & 17 & 33 \\
& Engenharia Mecânica & 1 & 8 & 42 \\
Exatas & Engenharia Química & 2 & 17 & 58 \\
Biológica & Química & 4 & 33 & 92 \\
\hline Totais & Odontologia & 1 & 8 & 100 \\
\hline
\end{tabular}

Fonte: INTECPONTA, 2009.

Tabela 5 - Perfil educacional por nível de escolaridade dos spin-offs acadêmicos da INTECPONTA - 2009

\begin{tabular}{lccc}
\hline $\begin{array}{l}\text { Número de } \\
\text { sócios }\end{array}$ & Quantidade & $\%$ do total & $\%$ acumulada \\
\hline Um & 1 & 20 & 20 \\
Dois & 1 & 20 & 40 \\
Três & 3 & 60 & 100 \\
Quatro & & & \\
Cinco & & 100 & \\
\hline Totais & 12 & \\
\hline
\end{tabular}

Fonte: INTECPONTA, 2009.

contrariando os estudos publicados que afirmam que a maioria dos spin-offs acadêmicos estudados situam-se próximos às universidades de origem. Esta diferença pode estar relacionada ao fato de a amostra ser pequena. Por mais que estejam distantes da universidade, possuem relações com o meio acadêmico, são professores/pesquisadores, e também porque as universidades são fontes contínuas de informação, e devido à relação existente entre os sócios e as instituições acadêmicas. E um localiza-se dentro da universidade de origem da pesquisa, também é conduzido por professores/pesquisadores, e utiliza os laboratórios e serviços técnicos das universidades.

Dois projetos já fizeram testes em indústrias, e estão prospectando clientes e novos fornecedores de matéria-prima. Deste dois, somente um está em fase de tranferir a tecnologia ou venture capital e angels, através de relações com investidores em negociações.
Já o outro está buscando apoio financeiro, o qual permita investir no desenvolvimento do demonstrativo funcional do produto.

Destaque em relação à inovação para o grupo Nanoita, Spin-off acadêmico da amostra estudada, coordenado pelo professor/pesquisador e empreendedor Dr. Sergio Mazurek Tebcherani, e liderada pelo doutorando Thiago Sequinel, atualmente na Universidade Estadual Paulista (UNESP). A equipe Nanoita é responsável pela criação, produção e comercialização de cerâmicas de revestimento (pisos e azulejos) impregnadas com agentes bactericidas. 0 diferencial da proposta foi o método de produção das peças, que utiliza tecnologias inovadoras a partir de nanoestruturas. As técnicas são patenteadas e detêm domínio de propriedade industrial. As cerâmicas desenvolvidas visam atender espaços como hospitais, clínicas, laboratórios, entre outros. Além de Thiago, que defendeu o Brasil na fase mundial do concurso, integram o grupo Sergio Tebcherani, da UEPG, e Rene José Rodrigues Fernandes, da FGV (coordenadores); José Arana Varela, da Unesp (orientador de doutorado de Sequinel); Elson Longo, da Unesp (responsável pela caracterização do produto); Silvana Souza Netto Mandalozzo, da UEPG (responsável jurídica); João Luiz Kovaleski, da UTFPR (responsável pela transferência tecnológica do produto); e o empresário Gustavo Ângelo Mandalozzo (Itajara Minérios) (FINEP, 2009).

O Brasil conquistou pela primeira vez a premiação máxima na competição Idea to Product (Da Ideia ao Produto), a qual acontece anualmente desde 2001. A competição foi fundada na Universidade do Texas, em Austin, pelo Presidente da Free Enterprise. 
O objetivo é a educação e desenvolver a próxima geração de empresários de tecnologia. 0 programa está particularmente interessado em combinar tecnologias resultantes dos programas de uma universidade de investigação fundamental em mercados potenciais. O produto do Nanoita foi considerado o melhor entre outros apresentados por 15 universidades da Ásia, Europa, América do Norte e América do Sul. "Esse prêmio coloca o Brasil em igualdade de desenvolvimento com os países de primeiro mundo, mas entendemos que esta conquista não diz respeito somente aos pesquisadores em questão, mas principalmente às ações governamentais que foram aplicadas corretamente", diz Sergio Mazurek Tebcherani, coordenador do time vencedor. Ele conta que o desenvolvimento do projeto só foi possível devido ao apoio recebido por meio da Lei da Inovação e do Programa de Subvenção Econômica da FINEP (FINEP, 2009).

Através da conquista do prêmio, o grupo Nanoita proporcionou visibilidade e reconhecimento internacional para a cidade de Ponta Grossa, para a UEPG e parceiras/INTECPONTA, CNPq, FINEP, e para a empresa Itajara Minérios Ltda. 0 destaque Spin-off acadêmico reforça a qualidade e o potencial da região para pesquisa e desenvolvimento científico e tecnológico, que deverão ser reforçados após a instalação do Parque Tecnológico, previsto para ser inaugurado em 2012.

\section{Considerações finais}

Desde a sua fundação, a incubadora estudada já acolheu sete empresas. Deste total, dois não eram spin-offs acadêmicos, portanto, os resultados aqui apresentados se referem a cinco spin-offs acadêmicos oriundos das universidades de Ponta Grossa e incubadas na INTECPONTA.

De forma sintetizada, afirma-se que $100 \%$ dos spin-offs acadêmicos têm idade superior a cinco anos, foram criados a partir de 2004, dentro dos laboratórios e salas de aula da universidade. De acordo com o critério do SEBRAE, registrou-se que $100 \%$ são considerados micro e pequenas empresas de base tecnológica e que a maior parte dos spin-offs acadêmicos da amostra possui três sócios. E por serem resultados de pesquisas altamente inovadoras, necessitam de proteção, a maior parcela, ou seja, $60 \%$ possui patentes depositadas (total ou partes dos produtos/ processos), e foram realizados em parceria com a agência de inovação da universidade.
Além disso, quatro utilizaram ou utilizam recursos próprios, e apenas um beneficiou-se de dinheiro público com projetos contemplados pelas instituições de fomento. Destaca-se também que neste spin-off acadêmico ocorreu a cooperação entre empresa, universidade/incubadora e governo. E nenhum recebeu apoio financeiro de capital de risco. Sendo caracterizado pela alta qualificação dos pesquisadores/ empreendedores envolvidos e revelando que 100\% são formados em áreas técnicas de biomateriais, nanotecnologia e ambiental, confirmando a importância de apoio e capacitação em gestão aos empreendedores incubados.

Entretanto, dos cinco spin-offs acadêmicos da amostra, dois encerraram suas atividades por dificuldades encontradas. Somente três continuam com suas atividades, e o número de empregos gerados são oito e todos os sócios são professores/pesquisadores ou possuem relações com as universidades de Ponta Grossa. Destes, dois estão incubados não residentes alocados em espaço próprio e longe da universidade de origem da pesquisa, e um localiza-se dentro da universidade de origem da pesquisa, utilizando os seus laboratórios e serviços. Para retorno financeiro, dois projetos realizaram testes em indústrias. Destes, somente um está em fase de transferir a tecnologia ou receber capital de risco. 0 outro está buscando apoio financeiro.

É possível observar que os spin-offs acadêmicos são mecanismo de transferência de tecnologias geradas nas universidades para a sociedade, e os atores envolvidos precisam apoiar e incentivar, para que os seus benefícios possam ser gerados em um menor tempo. Assim, surgirão mais spin-offs acadêmicos e maior será o impacto que proporcionarão à sociedade em desenvolvimento social e econômico.

Neste mundo dos spin-offs acadêmicos, de negócios dinâmicos e em constantes mudanças, as incubadoras proporcionam aos empreendedores/pesquisadores condições para desenvolver seus produtos inovadores e seus negócios, preparando-os para conquistar o mercado, gerar emprego, renda e desenvolvimento para suas comunidades.

Os esforços empreendidos pelas incubadoras no sentido de estabelecer parcerias visam ampliar a capacidade dos projetos incubados a desenvolver esses novos produtos. Essa nova dinâmica do conhecimento e inovação evidencia a importância das novas empresas estarem capacitadas para o mercado. E o sucesso dessas futuras empresas dependerá 
dos trabalhos de acompanhamento e monitoramento realizado pelas incubadoras, envolvendo atividades das universidade-empresa-governo, para que muitos desses mecanismos não deixem de existir.

Por fim, cabe ressaltar que um dos benefícios é a possibilidade de crescimento das incubadoras, podendo assim fomentar essa cooperação, tornando os spin-offs acadêmicos empresas de sucesso. Estabelecer esforços para elaboração e aplicação de uma metodologia para que, desde o início da vida acadêmica, os alunos vislumbrem a possibilidade de aproveitar as pesquisas e tecnologias disponíveis nas universidades, fica como sugestão para projetos futuros.

\section{Referências}

ASSOCIAÇÃO NACIONAL DE ENTIDADES PROMOTORAS DE EMPREENDIMENTOS INOVADORES - ANPROTEC. Novas bases para o crescimento. Revista Locus, Brasília, ano 15, n. 50, 2009.

ASSOCIAÇÃO NACIONAL DE ENTIDADES PROMOTORAS DE EMPREENDIMENTOS INOVADORES - ANPROTEC. O que são as incubadoras de empresas e parques tecnológicos. 2010. Disponível em: <http://www.anprotec.org.br/ publicacaoconheca.php?idpublicacao $=79>$. Acesso em: 22 out. 2010.

AZEVEDO, G. C. I. Transferência de tecnologia através de spin-offs: os desafios enfrentados pela UFSCar. 2005. $149 \mathrm{f}$. Dissertação (Mestrado em Engenharia de Produção) Universidade Federal de São Carlos, São Carlos, 2005.

CHIESA, V.; PICCALUGA, A. Exploitation and diffusion of public research the case of academic spinoff companies in Italy. R\&D Management, v. 30, n. 4, p. 329-340, 2000.

COSTA, L. B.; TORKOMIAN, A. L. V. Um estudo exploratório sobre um novo tipo de empreendimento: os spin-offs acadêmicos. Revista de Administração Contemporânea, v. 12, n. 2, p. 395-427, 2008.
FINANCIADORA DE ESTUDOS E PROJETOS - FINEP. Notícias. 2009. Disponível em: <http://www.finep.gov.br/ imprensa/noticia.asp?cod_noticia=2045>. Acesso em: 10 jun. 2010.

INCUBADORA TECNOLÓGICA DE PONTA GROSSA INTECPONTA. Plano de Negócios, 2009.

OLIVEIRA, A. R. de; CAULLIRAUX, H. M. Uma proposta de modelo cooperativista que relacione universidade e empresa. In: ENCONTRO NACIONAL DE ENGENHARIA DE PRODUÇÃO, 27., 2007, Foz do Iguaçu. Anais... Foz do Iguaçu: ENEGEP, 2007. Disponível em: <http://www.abepro.org.br/biblioteca/ENEGEP2007_TR630473_0363. pdf >. Acesso em: 19 mar. 2009.

REDE PARANAENSE DE INCUBADORAS E PARQUES TECNOLÓGICOS - REPARTE. Associados. Disponível em: $<$ http://www.reparte.org.br/associados/>. Acesso em: 11 jul. 2009.

SHANE, S. Academic entrepreneurship: university Spinoffs and wealth creation. Northampton: Edward Elgar Publishing, 2004. Disponível em: <http://books.google. com.br $/$ books?id $=$ Cg88SnPDvhUC\&printsec $=$ frontcove $\mathrm{r} \& \mathrm{dq}=$ University + Spin-offs + and + Wealth + Creation\&hl= pt-BR\&ei=v7PJTKn0HoWKlwem2ISiAQ\&sa=X\&oi=book result\&ct=book-thumbnail\&resnum $=1 \& \mathrm{ved}=0 \mathrm{CC} 4 \mathrm{Q} 6 \mathrm{wEw}$

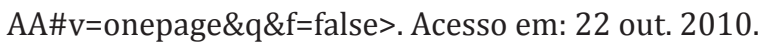

STEFFENSEN, M.; ROGERS, E. M.; SPEAKMAN, K. Spin-offs from research centers at a research university. Journal of Business Venturing, v. 15, n. 1, p. 93-111, 2000.

TERRA, B. A transferência de tecnologia em universidades empreendedoras: um caminho para a inovação tecnológica. Rio de Janeiro: Qualitymark, 2001.

Recebido: 01/08/2011

Received: 08/01/2011

Aprovado: 28/09/2011

Approved: 09/28/2011 